\title{
Percepção dos
}

\section{consumidores portugueses} sobre estereótipos de gênero nos argumentos publicitários verbais e não verbais

\author{
Melissa PIO (1)
}

๖

OPEN ACCESS

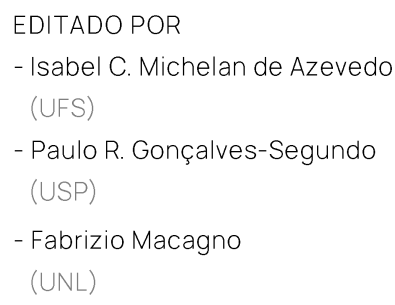

Universidade Nova de Lisboa - FCSH

\section{RESUMO}

Os estereótipos, com sua característica heurística, têm sido amplamente utilizados na publicidade ao longo das décadas. Porém, essa forma de fast reasoning torna-se facilmente falaciosa na medida em que faz uso de generalizações, muitas vezes implícitas, e de internalizações vigentes no contexto cultural no qual as mensagens estão inseridas, levando os consumidores a certas conclusões, nem sempre fundamentadas. Dentre os estereótipos mais utilizados pelos anunciantes estão os estereótipos de gênero. E, apesar de estudos recentes evidenciarem uma diminuição da sua presença nas mensagens das marcas, essa redução não é significativa. Além disso, quando tratado, este tema é mais comumente explorado do ponto de vista da análise de conteúdos, deixando assim uma lacuna no que diz respeito à recepção que os consumidores fazem destes estereótipos, tanto em um âmbito internacional, quanto no contexto português. Este estudo tem como objetivo começar a diminuir essa lacuna, através de um estudo piloto que mensurou como os consumidores residentes em Portugal avaliam o grau de estereotipia de gênero nos argumentos verbais e não verbais de anúncios fictícios, levantando evidências de qual elemento, o texto verbal ou a imagem, tem um papel mais preponderante nessa avaliação. Isso foi feito através de dois questionários, um com graus de estereótipos de gênero variando no texto verbal e o outro na imagem. Como 


\section{REVISTA DA ABRALIN}

resultado, pudemos levantar evidências de que o texto verbal parece deixar a presença de estereótipos de gênero mais clara para os respondentes que, por sua vez, tiveram mais facilidade em reconhecer estereotipias ligadas ao status ocupacional.

\section{ABSTRACT}

Stereotypes, with their heuristic characteristic, have been widely used in advertising over the decades. However, this form of fast reasoning becomes easily fallacious as it makes use of generalizations, often implicit, and current internalizations of the cultural context in which messages are inserted, leading consumers to certain conclusions, which are not always supported by evidence. Among the most used stereotypes by advertisers are gender stereotypes. And, despite recent studies showing a decrease in their presence in brand messages, this reduction is not significant. Furthermore, when dealt with, this theme is more commonly explored from the point of view of content analysis, thus leaving a gap regarding the reception that consumers make of these stereotypes, both internationally and in the Portuguese context. This study aims to begin to reduce this gap, through a pilot study that measured how residents in Portugal assess the degree of gender stereotyping in verbal and non-verbal arguments of fictitious advertisements, raising evidence of which element, the verbal text or the image, has a more important role in this evaluation. This was done through two questionnaires, one with the degrees of gender stereotypes varying in the verbal text and the other in the image. As a result, we were able to raise evidence that the verbal text seems to make the presence of gender stereotypes clearer for respondents who, in turn, found it easier to recognize stereotypies linked to occupational status.

\section{PALAVRAS-CHAVE}

Publicidade. Estereótipos de gênero. Recepção. Estudo piloto. Portugal.

\section{KEYWORDS}

Advertising. Gender stereotypes. Reception. Pilot study. Portugal. 


\section{REVISTA DA ABRALIN}

\section{Introdução}

Ao defenderem uma conclusão prática ou de validação, as mensagens publicitárias são, em seu cerne, formas de argumentação. No entanto, por seu aspecto ágil, resposta ao desafio de captar rapidamente a tão disputada atenção dos consumidores, é usual que a publicidade se faça valer de generalizações que poderiam ser facilmente discutidas. Não é incomum, inclusive, encontrar em anúncios de produtos e serviços o uso de hasty generalizations, um tipo de falácia que, quando combinada com certos elementos argumentativos implícitos ou explícitos, acaba por gerar uma tática sofisticada que aumenta a possível aceitação do argumento, através do poder da sugestão (WALTON, 1999). Se aceitarmos a definição de Hurley (1997) de que uma hasty generalization é uma falácia que induz a generalizações e que a definição dessa indução aponta para "an argument that draws a conclusion about all members of a group from evidence that pertains to a selected sample" (HURLEY, 1997, p. 142), então é possível aproximar desta falácia o conceito de estereótipos. Isso porque os estereótipos são também generalizações, usualmente internalizadas na cultura vigente e que, portanto, se encontram muitas vezes no ponto cego de uma avaliação crítica. Assim, os consumidores das mensagens publicitárias que utilizam este tipo de argumentação, podem ser levados a conclusões problemáticas não apenas por sua natureza possivelmente falaciosa, mas porque, dentre as consequências do uso de estereótipos, está o perigo de se prejudicar o grupo ao qual aquele estereótipo se direciona.

E, embora existam diversos tipos de estereótipos, há um que é mais comum que todos na publicidade: os estereótipos de gênero. Kachel, Steffens e Niedlich (2016) definem que estereotipia de gênero é a prática de se descrever homens e mulheres através de atributos, características ou papéis específicos, tendo como base apenas o fato deles pertencerem ao grupo social de homens e ou de mulheres. O mesmo fenômeno também pode ser encontrado na literatura através do conceito "papéis de gênero" que igualmente descreve a crença de que certos atributos diferenciam homens e mulheres (EISEND, 2019). Sendo o gênero uma construção social que muitas vezes têm um papel central na construção da identidade dos indivíduos (BUTLER, 1990) é importante continuar a se discutir os estereótipos de gênero sob diversas vertentes, uma vez que o conceito comumente acaba por simplificar demasiadamente um fenômeno complexo. Quando utilizado na publicidade, seu efeito pode ser ambíguo, possivelmente trazendo alguns benefícios na avaliação das marcas, ao mesmo passo que pode causar desvantagens especialmente para as mulheres, mais frequentemente representadas em papéis idealizados (EISEND, 2019) ou sub-hierarquizados (GOFFMAN, 1979). Não à toa, as pesquisas sobre publicidade têm, já há cerca de cinco décadas, discutido e estudado o uso dos estereótipos de gênero (GRAU; ZOTOS, 2016). Porém, ainda assim, estudos recentes mostram que embora o grau de estereotipia utilizado na comunicação das marcas tenha diminuído um pouco, o uso de papéis de gênero tradicionais na publicidade ainda é uma prática habitual (FURNHAM; MAK, 1999; FURNHAM; PALTZER, 2010; GRAU; ZOTOS, 2016; EISEND, 2019), inclusive em Portugal (VERÍSSIMO; PEREIRA, 2006; PEREIRA et al., 2013; JORGE; CERQUEIRA; MAGALHÃES, 2014; PIO, 2019; FERREIRA; LOBO; PIO, 2021). É também notório o fato de que os estudos anteriores voltados à representação dos gêneros na publicidade são predominantemente focados em análises de conteúdo, o que 


\section{REVISTA DA ABRALIN}

deixa uma lacuna do lado da recepção do público diante destas mensagens e da produção publicitária, onde elas surgem (GRAU; ZOTOS, 2016). E, muito embora as pesquisas baseadas em análises de conteúdo sejam importantes para que se possa avaliar continuamente a evolução das representações de homens e mulheres nas mensagens publicitárias (EISEND, 2019), é também necessário discutir a questão de forma mais abrangente, criando assim uma literatura mais robusta também no campo da recepção e da produção. O objetivo deste estudo é contribuir para a diminuição de uma destas lacunas, ao realizar dois questionários piloto voltados à recepção, com foco em avaliar qual é a mensuração que os consumidores fazem de diferentes graus de estereotipia de gênero em anúncios publicitários. Mais especificamente, interessa-nos também levantar evidências sobre qual estímulo, o texto verbal ou a imagem, influencia mais na sua percepção quanto à presença de estereótipos de gênero nos argumentos dos anúncios.

Para este efeito, este artigo apresentará uma revisão bibliográfica do uso dos estereótipos de gênero na publicidade, destacando também alguns dos principais papéis de gênero encontrados nas pesquisas do campo. A seguir, apresentaremos uma base teórica voltada ao uso e estudo da argumentação multimodal na publicidade de produtos e dos estereótipos na argumentação publicitária. Dessa base teórica, foram escolhidas algumas representações estereotipadas e contra estereotipadas para o gênero masculino e para o gênero feminino, que podem ser expressas tanto em argumentos verbais quando em não verbais, a partir dos quais foram criados, em maio de 2020, dois conjuntos de anúncios publicitários fictícios para um mesmo produto, diminuindo assim o risco de os respondentes terem alguma experiência ou avaliação prévia que poderiam influenciar a sua avaliação. No primeiro conjunto, a presença de estereótipos de gênero se dá nas imagens, enquanto no segundo os estereótipos de gênero estão presentes no texto verbal. Cada um destes conjuntos foi utilizado em dois questionários piloto cujos resultados serão apresentados na segunda seção deste artigo, após a apresentação mais aprofundada da metodologia deste estudo. Ao final, apresentaremos os resultados e conclusões referentes a ambos os questionários, seguido das aprendizagens e melhorias a serem realizadas no questionário. Por fim, apresentaremos as conclusões gerais sobre os caminhos apontados pelos questionários pilotos.

\section{Base teórica}

\subsection{Histórico dos estereótipos de gênero na publicidade}

É principalmente após a segunda vaga do feminismo, nos anos 1960, que diversos pesquisadores voltaram o seu olhar para a publicidade em busca de entender como homens e mulheres eram então representados. Estudos clássicos como o de McArthur e Resko (1975) revelaram que as mulheres, por exemplo, eram frequentemente mostradas em ambientes caseiros e perpetuadas como dependentes. Isso mostra a estreita relação entre as representações dos papéis de gênero na publicidade e a maneira como cada um deles se associava, e até hoje se associam, às esferas pública e privada uma vez 


\section{REVISTA DA ABRALIN}

que, assim como apontam os historiadores Ariès e Duby (1985), desde muito cedo na história, a diferença entre o masculino e o feminino está "fortemente ancorada na distinção entre o exterior e o interior, entre o público e o privado" (pp. 9-10). Também a pesquisa conduzida por Williamson (1978) revelava que a domesticidade, fortemente ligada à esfera privada, era um dos significantes utilizados para representar as mulheres na publicidade. Até o fim da década de 1990 mais autores também apontaram a constante representação das mulheres em tarefas voltadas ao lar e aos cuidados (BOURDIEU, 1999; FURNHAM; MAK, 1999) ao passo que os homens eram mostrados em papéis profissionais em uma proporção quase duas vezes maior em relação às mulheres, perpetuando assim os ideais tradicionais de genderização das esferas (COLTRANE; ADAMS, 1997). Isso demonstra a permanência de uma hierarquia de funções, problemática já apontada por Goffman (1979) muitos anos antes. É também no decorrer da década de 1990 que se levantou com mais veemência a constante objetificação feminina enquanto um produto sexual a ser livremente observado, julgado e manipulado (WOLF, 1992; LIN; 1997) perpetuando-se assim o potencial da publicidade de produzir imagens distorcidas nas mulheres, expostas a ideais irreais de beleza e peso mostrados pelas marcas (LAVINE; SWEENEY; WAGNER, 1999; BESSENOFF; DEL PRIORE, 2007; OSTBERG, 2010), tema muito discutido nas pesquisas realizadas na virada do século XX para o XXI.

E, embora o gênero ainda seja um tema constante na academia, é notável a queda da quantidade de artigos publicados em revistas de referência entre 2010 e 2021 que tenham como foco a presença de estereótipos de gênero na publicidade, suas causas ou suas consequências. Aqueles que o fazem são, em grande parte, estudos de meta-análise ou revisões de bibliografia, que reúnem e comparam resultados advindos de pesquisas primárias conduzidas anteriormente por outros autores. Furnham e Paltzer (2010), por exemplo, atualizaram um estudo realizado por Furnham e Mak (1999), analisando 30 estudos de diferentes países. A constatação é de que ainda existe uma má distribuição de funções profissionais nas representações de homens e mulheres na publicidade, com a tendência de que os homens sejam colocados em papéis de autoridade nos anúncios. Grau e Zotos (2016), por sua vez, descrevem como as análises de conteúdo realizadas anteriormente apontam para quatro principais categorias nas quais se encaixam os estereótipos de gênero. São elas as características físicas (como a magreza nas mulheres), o status ocupacional (como homens em cargos profissionais), os papéis sociais (mulheres como cuidadoras e homens como líderes, por exemplo) e traços de personalidade (como a representação do homem independente). Os autores concluem que é mais comum encontrar a representação de homens em posições de liderança e autoridade, e não tanto em contextos que colocam a preocupação com a estética como foco, enquanto as mulheres são mais comumente retratadas em papéis familiares e funções decorativas, muitas vezes ligadas a atributos físicos como a beleza e a magreza.

As evidências de alguns estudos conduzidos na segunda década dos anos 2000 também demonstram que a utilização dos papéis de gênero na publicidade é um fenômeno universal, como apontam Matthes, Prieler e Adam (2016) ao cruzar os resultados encontrados na análise das representações de gênero de 13 países. Eisend (2019), por sua vez, embora concorde com a extensiva presença destes papéis de gênero na publicidade, também aponta para a existência de algum grau de pressão física 


\section{REVISTA DA ABRALIN}

ligada à masculinidade e não apenas à feminilidade. Porém, não de forma simétrica, uma vez que o ideal masculino, neste caso, não é a magreza como acontece com a representação do ideal feminino, mas sim a força. O autor argumenta também que existe uma escassez de pesquisas voltadas à presença e caracterização dos estereótipos masculinos na comunicação publicitária. Ideia semelhante pode ser encontrada no trabalho de Grau e Zotos (2016) embora os autores apontem estudos realizados por Marshall et al. (2014), e Fowler e Thomas (2015) que de fato são exclusivamente voltados aos estereótipos masculinos presentes na publicidade. E, embora alguns autores apontem para a existência de uma tendência de se mostrar cada vez mais homens em contextos familiares, como pais, ainda continua a prevalecer uma representação mais tradicional da masculinidade. O'Driscoll (2019), por exemplo, aponta para a repetitiva utilização de um estereótipo masculino que nomeia como "bumbling idiot", ou seja, a representação de homens como seres inaptos no que diz respeito ao cuidado do lar e dos filhos.

Já nos últimos anos, e com o crescimento ainda em curso das redes sociais, as análises têm cada vez mais focado na comunicação das marcas na internet e não mais somente nos comerciais de televisão e anúncios em revistas impressas. As novas mídias abrem, assim, um novo ponto de discussão. Como argumentam Bivens e Haimson (2016), as plataformas de mídias sociais acabam tendo um significativo potencial de controlar e gerar categorizações mais amplas de gênero, uma vez que atuam muitas vezes como mediadoras entre as necessidades de seus usuários e as expectativas de seus anunciantes. Também por isso, há um crescente interesse por parte da academia em estudar o papel dos algoritmos na genderização da exposição dos anúncios nestas plataformas. Um exemplo foi o estudo conduzido por Lambrecht e Tucker (2019), que explorou a distribuição de anúncios de empregos de áreas como ciências, matemática, tecnologia e engenharia entre homens e mulheres e comprovou uma "genderização" do algoritmo. No entanto, ao que tudo indica, este é um resultado cumulativo e não uma migração total dos papéis de gênero de um meio para o outro. Isso porque a genderização que se observa nos meios digitais não deixou de existir nas mídias tradicionais, que continuam a perpetuar papéis tradicionais de gênero que vão desde o jornalismo (LOBO, 2011) até a sua ainda atual presença na publicidade (FURNHAM; MAK, 1999; FURNHAM; PALTZER, 2010; GRAU; ZOTOS, 2016; EISEND, 2019).

E, embora em Portugal a academia de ciências sociais tenha virado o seu foco para as questões de gênero com algum atraso quando comparado aos Estados Unidos e outros países europeus (AMÂNCIO, 2003), este é hoje tema recorrente na pesquisa de alguns autores no país. Focados mais especificamente em publicidade estão, por exemplo, Pereira e Veríssimo (2008), que evidenciaram a presença e as distinções de papéis de gênero nas mensagens publicitárias ainda que, assim como autores internacionais citados anteriormente, tenham também notado uma pequena diminuição da sua ocorrência ao longo do tempo. Do lado da recepção, a sua pesquisa apontou para a existência de uma consciência da presença de estereotipias na publicidade por parte de estudantes do ensino superior, porém com evidências de que alguns destes estereótipos já foram interiorizados por parte do público pesquisado. Este resultado é semelhante ao encontrado por Jorge, Cerqueira e Magalhães (2014), que constatam também a ausência de uma postura disruptiva por parte dos alunos. Mota- 


\section{REVISTA DA ABRALIN}

Ribeiro (2010), por sua vez, apontou para como a publicidade perpetua as desigualdades de gênero através da forma como as mulheres são representadas nas imagens. Esta autora também aponta para uma coexistência de discursos mais tradicionais e expressões novas no que se refere ao gênero e sua representação, porém deixando claro que o aparente poder que muitas imagens publicitárias dão à mulher é, na realidade, um poder subjugado por idealizações, o que acaba por reduzir a liberdade feminina e não por a ampliar. Isso porque é comum que este "poder" seja atribuído através do corpo que, como também apontam Santos (2016), Veríssimo (2008) e Magalhães (2014), é muitas vezes colocado como tema central da vivência feminina, especialmente no discurso publicitário. E, mesmo quando o corpo apresentado nas mensagens publicitárias é o masculino, a objetificação não é feita de forma simétrica pois, como demonstram Figueiredo e Pacheco (2018), mesmo o homem objetificado ainda é mostrado como dominante, ao contrário da passividade com que a mulher objetificada é retratada.

Estudos ainda mais recentes demostram a persistência no uso de alguns estereótipos de gênero nas mensagens. Sejam eles através de uma falsa reversão de papéis, que acaba por apenas ocultar a presença de modelos tradicionais (PIO, 2019) ou através da localização clássica da mulher no espaço privado ou em posições de cuidado, enquanto o homem é representado no espaço público, exercendo atividades profissionais, inclusive no contexto de confinamento imposto pela pandemia de Covid-19 (FERREIRA; LOBO; PIO, 2021).

O panorama português, portanto, não difere muito daquele mostrado pelas pesquisas internacionais de que, embora o uso de papéis tradicionais de gênero na publicidade tenha vindo a diminuir, as permanências são mais significativas do que as alterações.

\subsection{0 texto verbal e não verbal na publicidade}

A ideia de que a argumentação multimodal descreve uma manifestação de significados através de modos semióticos plurais (MACAGNO; PINTO, 2020) vai de encontro com a visão sociointeracionista de que o texto é, muito além da escrita, uma entidade multifacetada (MARCUSCHI, 2003). Assim, o texto passa a ser entendido como um ato discursivo compartilhado e co-criado pelos interagentes, através da sua contextualização, e que também é formado não apenas por elementos verbais, mas por diversos modos semióticos e seus diferentes recursos que se entrelaçam para constituir o todo (KRESS, 2010; TSERONIS; FORCEVILLE, 2017). Portanto, é perfeitamente aceitável a ideia de que a linguística deve dialogar constantemente com ciências focadas em outros sentidos e, dentre elas, a semiótica (CAVALCANTE; CUSTÓDIO FILHO, 2010), base do conceito de multimodalidade. De fato, já Toulmin (1958) considerava que abordar a argumentação apenas através de uma lógica formal não basta para que se alcance uma descrição suficientemente boa de seu funcionamento. E, seja a argumentação uma ferramenta de resolução de opiniões discrepantes (VAN EEMEREN; GROOTENDORST, 2002), seja a aderência que o público tem a certa ideia (ADAM; BONHOMME, 1997) ou um meio de se solucionar conflitos e diferenças entre duas ou mais partes (WALTON, 1990), o que parece 


\section{REVISTA DA ABRALIN}

ser um consenso crescente é a pertinência de se estudar como a argumentação é constituída e mediada tanto por modalidades verbais como por modalidades imagéticas que, por sua vez, possuem recursos e limitações distintos. E isso em campos que vão desde a linguística (KRESS, 1977; 1987) e a semiótica social (HALLIDAY, 1978), até a proposta da existência de uma gramática visual (KRESS; VAN LEEUWEN, 1996; 2006).

Neste pivô, dos estudos de argumentação fortemente baseados nos elementos verbais, para uma perspectiva que considera os elementos visuais como também possuidores de uma forte componente retórica, destaca-se o trabalho de Blair (1996) que defende não apenas uma função argumentativa das imagens, mas a existência de uma argumentação visual, na qual as premissas e conclusões, antes teorizadas no modelo tradicional de argumentação verbal, existem igualmente, porém expressadas visualmente. Mendes (2013) vai além e, tendo como base a ideia de que argumentar é procurar recursos que levem à persuasão, afirma que as imagens acabam revelando sua dimensão argumentativa justamente por não apresentarem de forma tão explícita seus mecanismos de argumentação.

E justamente na intersecção entre persuasão e argumentação encontra-se, muitas vezes, a publicidade. Aliás, é a sua própria natureza persuasiva que acaba por fazer com que este seja um campo fértil de produção e análise de como a multimodalidade argumentativa é desenvolvida e percepcionada. Porém, a pluralidade de enquadramentos possíveis de serem usados ao se analisar os significados explícitos ou implícitos em diferentes elementos presentes nas mensagens publicitárias, sendo eles verbais ou não, acaba por criar um contexto complexo. É justamente diante dessa complexidade que Macagno e Pinto (2020), por exemplo, propõem um esquema metodológico que permite que a análise da argumentação duo-modal na publicidade, neste caso entre os modos verbais e visuais, seja feita através da combinação entre uma perspectiva pragmática e o uso de ferramentas da teoria da argumentação. Outros autores, como Pollaroli e Rocci (2015) argumentam que a publicidade de produtos utiliza, muitas vezes, uma estrutura genérica de argumentação, quase sempre baseada em argumentações focadas no practical reasoning ou em argumentos means-end.

No entanto, ainda que os textos verbais e não verbais sejam muitas vezes explícitos no apoio que fazem ao ponto de vista defendido nos anúncios, eles podem muito bem ser também implícitos, o que faz com que a avaliação sofra uma intervenção vital do consumidor, que acaba por completar o sentido das mensagens de acordo com o seu próprio contexto e conhecimento prévio. Dessa forma, mesmo que a publicidade utilize o que os autores chamam de template argumentativo, isso não torna o processo de análise mais simples, uma vez que a "responsabilidade interpretativa" que o receptor possui no entendimento dos argumentos multimodais acaba por adicionar grande complexidade à questão. E, embora os argumentos verbais e não verbais sejam usualmente interpretados de forma conjunta pelo receptor, nos parece essencial avaliá-los em separado quando o objetivo é aprender a sua influência individual em determinado fenômeno, como é o caso do estudo piloto por nós desenvolvido. De fato, autores como Blair (1996) e Groarke (1996) acreditam que a componente visual das argumentações multimodais não é apenas uma ilustração da componente verbal, mas um argumento em si. Portanto, se cada um destes elementos possui uma estrutura argumentativa própria, é possível também avaliá-los separadamente. 


\section{REVISTA DA ABRALIN}

\subsection{0 uso de estereótipos na argumentação publicitária}

Assim como apontam Macagno e Pinto (2020), dentre os princípios utilizados na análise de textos verbais e não verbais, existe um que leva em consideração o fato de que este texto foi produzido dentro de uma prática social específica. Assim sendo, a produção e interpretação deste texto são feitas através de modelos internalizados previamente por aqueles que o produzem e interpretam. Portanto, é muito importante estudar os aspectos extralinguísticos da argumentação como, por exemplo, os elementos contextuais e culturais em que essa argumentação está inserida, perspectiva também defendida por van Eemeren (2011). E, um dos fenômenos que parecem ser mais internalizados na cultura passada e presente, de forma bastante global, é justamente o do uso dos estereótipos. O problema reside no fato de que estereótipos são muitas vezes utilizados como a premissa principal de diversos argumentos, utilizando-se de generalizações para levar os receptores a chegarem a certas conclusões. Porém, justamente por sua característica generalista, além de seu uso indiscriminado e sem uma avaliação crítica, os estereótipos são na realidade argumentos facilmente atacáveis, uma vez que sua generalidade faz com que sejam destituídos de real evidência. Assim, os estereótipos acabam sendo uma forma de fazer com que os recipientes cheguem rapidamente à uma conclusão. Porém, essa conclusão, além de não ser totalmente fundamentada, pode também estar imbuída de algum grau de preconceito, o que pode ser extremamente problemático. Quatohoff (1978), por exemplo, chega a apontar que o preconceito é não apenas um elemento presente nos estereótipos, mas a sua maior característica. Seja como for, o autor argumenta que a característica dos estereótipos de serem julgamentos baseados em generalizações exageradas, faz com que este seja um fenômeno desaprovado por todos, mas que ninguém parece conseguir deixar de utilizar. Isso ocorre, muito possivelmente, porque, assim como aponta Tanaka (1994), as pessoas desejam identificar e processar as informações que acessam da forma mais eficiente possível. Os estereótipos, portanto, podem parecer um caminho inevitável do processo de compreensão, pelo menos enquanto estiverem internalizados de forma pouco contestada na sociedade. Isso porque estereótipos são uma forma de fast reasoning e heurísticos por natureza. Portanto, agem como regras práticas que permitem uma resolução rápida a um problema, mesmo diante da falta de informações para que essa resolução seja a melhor possível. O problema é que a heurística pode conter vieses, assim como pode induzir os receptores ao erro (WALTON, 2010).

No entanto, se a efetividade e rapidez em se passar uma mensagem são também características da publicidade, não é de estranhar a presença constante de estereótipos nas mensagens das marcas, especialmente os de gênero, como demonstra a literatura comentada anteriormente. Assim, demonstrações de rituais de gênero parecem ser vistos pelos publicitários como uma solução "segura" diante da necessidade de simplificar a sua comunicação (WINDELS, 2016). Nesse caso, e como consequência das atribuições sociais assimétricas atreladas aos papéis de gênero, as mulheres acabam por ser mais afetadas pelo uso que a publicidade faz dos estereótipos (MIDDLETON; TURNBULL, 2021) ao incluir em seus argumentos certas premissas generalistas sobre este grupo (TANAKA, 1994), na tentativa de direcionar a interpretação que será feita dos anúncios, tendo como base conceitos 


\section{REVISTA DA ABRALIN}

já internalizados na sociedade como o papel da mulher no lar e na família, apenas para citar um exemplo. E, como aponta Tanaka (1994), a argumentação publicitária consegue fazer uma extensão ou até mesmo a alteração do significado de algumas palavras, através da sua utilização em determinado contexto. No Japão, coloca a autora, a palavra "inteligente", pode ser facilmente interpretada como "bem-vestida" quando ligada à cultura vigente e ao estereótipo de que, no país, as mulheres devem atender a um padrão estético específico. É possível argumentar que parte dessa extensão pode se dar através do uso da imagem, que ajuda a reforçar, mesmo que de forma implícita, conceitos internalizados pelo produtor da mensagem e também por quem vai interpretá-la. Ou seja: é possível que o texto verbal diga uma coisa, enquanto o texto visual aponta para outra, de forma a adicionar sentidos implícitos ao que está explícito na mensagem. De fato, não é incomum os estereótipos serem apresentados na publicidade de forma acobertada, deixando com que o receptor complete a mensagem através de conceitos internalizados. Afinal, explicitar estereótipos pode levar de forma mais acentuada à sua não aceitação do que quando o argumento supostamente deixa que o leitor complete a mensagem com a sua própria interpretação. É como quem diz "não fui eu quem disse, você é que leu assim", ainda que isso não seja inteiramente verdade, uma vez que todos os elementos da argumentação têm o seu próprio papel dentro do contexto em que se apresenta.

Portanto, interessa saber quais destes elementos textuais são interpretados de forma mais clara pelos consumidores, especialmente do ponto de vista dos estereótipos de gênero e a influência individual que cada um deles possui na interpretação que o público faz das mensagens publicitárias que tanto usam este recurso. Assim, torna-se possível analisar o contexto destas mensagens com os olhos do público, ou pelo menos se aproximar disso, sendo possível chegar a hipóteses mais assertivas quanto às possíveis consequências do uso dos estereótipos nos elementos verbais e não verbais da comunicação publicitária.

\section{Metodologia}

\subsection{Esquema da pesquisa}

Como forma de recolher dados a respeito da mensuração que o público residente em Portugal faz dos estereótipos de gênero na argumentação publicidade e da influência do texto verbal e da imagem nessa percepção, conduzimos um experimento piloto no qual dois questionários foram desenvolvidos, tendo como base o estudo de De Meulenaer et al. (2018) que foi, em parte, replicado. A opção de se usar questionários, portanto, foi primeiramente baseada no seu uso também no estudo original, no qual esta pesquisa se inspira. Além disso, e assim como apontam Dörnyei e Taguchi (2010), a aplicação de questionários pode ser uma forma eficiente, tanto do ponto de vista temporal quanto do ponto de vista financeiro, de se obter e analisar dados, algo vital para uma pesquisa piloto. Além disso, questionários são menos intrusivos e garantem maior anonimato aos participantes (IWANIEC, 2020), algo importante para pesquisas de temas sensíveis, como pode ser o caso do gênero. 


\section{REVISTA DA ABRALIN}

Seguindo o estudo original, cada um dos questionários apresentava anúncios fictícios para uma marca de refrigerante estrangeira, pouco conhecida em Portugal, com diferentes anúncios apresentando três graus de estereotipia de gênero, sendo dois anúncios neutros, dois anúncios com representações estereotipadas do gênero feminino, dois anúncios com representações estereotipadas do gênero masculino e dois anúncios considerados contra estereotípicos, um para cada um dos gêneros binários (masculino e feminino). Em um dos questionários a variação do grau de estereotipia era feita somente através da imagem, com uma assinatura verbal neutra e igual em todos os anúncios. No outro questionário, a variação era sempre feita através dos textos verbais, com imagens sempre diferentes, porém todas neutras. Nos dois questionários era solicitado aos respondentes que informassem o quão estereotipados eram cada um dos anúncios, através de uma perspectiva de gênero.

\subsection{Definição do produto e variáveis}

A escolha de usar um refrigerante nos anúncios foi baseada na indicação de estudos anteriores deste ser um produto neutro no que diz respeito ao gênero (AN; KIM, 2007). Já a Marca Faygo, refrigerante maioritariamente comercializado nos Estados Unidos e Canadá, assim como no estudo original de De Meulenaer et al. (2018), foi escolhida justamente por não suscitar familiaridade no público residente em Portugal uma vez que, como apontam os autores, isso poderia alterar o resultado das avaliações dos anúncios. Essa baixa familiaridade foi checada de maneira informal, anteriormente ao estudo, ao questionarmos 14 moradores do território português, de três nacionalidades diferentes (portuguesa, brasileira e polonesa), se eles conheciam Faygo. Destes, apenas dois reconheceram Faygo como sendo uma marca de refrigerante e, em ambos os casos, em contexto internacional, sendo um durante uma viagem e outro por ter morado nos Estados Unidos. Posteriormente, optamos por não enviar os questionários para estes dois respondentes da sondagem preliminar para que a sua familiaridade com a marca não interferisse nas avaliações.

As manipulações no grau de estereotipia de gênero utilizadas nos anúncios foram baseadas em pesquisas anteriores, sendo:

- Estereótipo da mulher como realizadora das tarefas domésticas (EISEND, 2010; GRAU; ZOTOS, 2016; URAY; BURNAZ, 2003; KNOLL, EISEND; STEINHAGEN, 2011);

- Estereótipo da mulher como cuidadora (GRAU; ZOTOS, 2016);

- Estereótipo da mulher sensual (WOLF, 1992; LIN, 1997; REICHERT; CARPENTER, 2004);

- Estereótipo do homem no trabalho (FURNHAM; MAK, 1999; KNOLL; EISEND; STEINHAGEN, 2011); 


\section{REVISTA DA ABRALIN}

- Estereótipo do homem que não sabe realizar afazeres domésticos e familiares (MARSHALL et al., 2014; O'DRISCOLL, 2019);

- Estereótipo do homem em posição de liderança (GRAU; ZOTOS, 2016).

Portanto, das quatro principais categorias de estereotipia apresentadas por Grau e Zotos (2016), optamos por utilizar neste estudo duas delas: a do status ocupacional, uma das mais utilizadas na publicidade, segundo De Meulenaer et al. (2018), e a dos papéis sociais. Estes estereótipos foram também a base para a escolha das imagens e textos verbais selecionados com o intuito de serem contra estereotipados, nos quais subvertemos alguns dos papéis. Quanto às variantes neutras, todas procuravam não apresentar nenhuma postura, ambiente ou indicação ocupacional que pudesse ter os traços que as pesquisas anteriores mostram como sendo estereotípicos numa perspectiva de gênero.

As fotografias utilizadas foram retiradas do banco de imagens Stock Adobe e complementadas com a imagem de uma garrafa do refrigerante Faygo, uma frase criada especificamente para cumprir com o objetivo deste estudo (comumente chamada na publicidade de tagline, slogan ou assinatura) e do logotipo da marca, como forma de tornar os anúncios mais realistas. ${ }^{1}$

\subsection{Coleta e análise de dados}

Os dois questionários foram desenvolvidos em português e distribuídos online, através de um formulário criado na plataforma Google Forms, primeiramente para dois grupos distintos com três pessoas cada, através de uma amostra por conveniência. Foi solicitado então que estes seis primeiros respondentes repassassem o formulário para outras pessoas que se adequassem aos critérios da pesquisa (ter mais de 18 anos e morar em Portugal), através da técnica snowball, chegando assim na amostra final ( $n=29$, sendo $n=15$ no questionário que tinha a imagem como variável e $n=14$ no inquérito que tinha o texto verbal como variável).

Na primeira parte dos questionários eram solicitados alguns dados demográficos como idade, sexo e distrito de moradia. Na segunda parte, os anúncios apareciam de forma randômica para os respondentes, que eram solicitados a darem a sua opinião sobre o quão estereotipado consideravam ser cada um dos anúncios, tendo em mente uma perspectiva de gênero. A medição da estereotipia era feita através de uma escala de Likert de sete pontos sendo (1) nada estereotipado e (7) extremamente estereotipado. A escolha por uma escala de sete pontos foi baseada em evidências de que essa é uma opção sensível o suficiente para refletir subjetividades de forma mais precisa que a bastante popular escala de 5 pontos, por exemplo, mas também compacta o bastante para que seja eficiente

\footnotetext{
1 Os anúncios criados podem ser vistos em: https://drive.google.com/file/d/1lhkEggaaQPjFGDB76frzUgoTx0YXs-

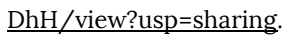




\section{REVISTA DA ABRALIN}

no sentido de os respondentes não abandonarem a pesquisa ao meio, especialmente em pesquisas conduzidas por meio eletrônico (FINSTAD, 2010). Por fim, na terceira e última parte do questionário, foram apresentadas questões fechadas e semiabertas sobre o questionário propriamente dito, com um campo de comentário ao final para que os respondentes pudessem apontar possíveis ambiguidades ou falta de clareza no questionário. Dessa forma, este piloto cumpriu não apenas uma função exploratória, mas também funcional, uma vez que a análise quantitativa e qualitativa dessa terceira parte nos permitirá afinar os questionários antes de realizar a próxima, e mais alargada, fase da pesquisa, em breve.

Por fim, e justamente por ser uma pesquisa piloto, com amostragem pequena, a análise dos dados foi feita de forma manual, após a exportação das respostas para uma tabela em Excel.

\subsection{Dados demográficos da amostra}

Demograficamente, os respondentes do inquérito que apresentava a variação dos graus de estereótipos nas imagens ( $\mathrm{n}=15)$ têm uma média etária de 31,42 anos (desvio padrão = 3.75) e estão distribuídos por cinco distritos de moradia: Lisboa $(n=6)$, Évora $(n=6)$, Setúbal $(n=1)$, Oeiras $(n=1)$ e Cascais $(n=1)$. Destes, apenas Évora se encontra um pouco abaixo da média nacional mensal recebida por trabalhadores por conta de outrem, situação da maioria da amostra $(n=13)$, segundo dados do Pordata ${ }^{2}$ referentes a 2010. Esta informação, juntamente com a recolha das informações de que a maioria da amostra consegue viver ou vive confortavelmente com o rendimento do agregado familiar ( $\mathrm{n}=8$ e $\mathrm{n}=6$, respectivamente) nos permitem assumir que o grau social dos participantes é de médio a elevado. Ademais, metade dos participantes responderam serem licenciados ou bacharelados $(n=7$ e $n=2)$ e estão proporcionalmente distribuídos entre o sexo feminino $(n=8)$ e o masculino $(n=7)$. No que diz respeito à nacionalidade, são em sua maioria portugueses $(\mathrm{n}=12)$, sendo os demais respondentes uma pessoa com dupla cidadania portuguesa e polonesa, um britânico e um brasileiro.

Já no questionário cujo grau de estereotipia estava presente nos textos verbais, os respondentes possuem uma faixa etária média de 32,42 anos (desvio padrão = 4.95), e distribuem-se entre Lisboa $(\mathrm{n}=11)$, Setúbal $(\mathrm{n}=2)$ e Porto $(\mathrm{n}=1)$, todos distritos com média mensal de rendimentos recebida por trabalhadores por conta de outrem $(\mathrm{n}=9)$ acima da média de Portugal, também segundo dados da Pordata ${ }^{3}$ referentes à 2010, informação mais recente disponível. Também nesta amostra os respondentes disseram ser possível viver ou viver confortavelmente com o rendimento disponível ao agregado familiar ( $n=6$ e $n=7$, respectivamente). A maior parte dos respondentes deste questionário havia concluído pelo menos um mestrado $(n=6)$ e é de nacionalidade brasileira $(n=10)$, sendo os demais participantes portugueses $(\mathrm{n}=3)$ e um deles angolano $(\mathrm{n}=1)$. Este questionário foi respondido por uma proporção maior de mulheres $(n=9)$ do que de homens $(n=5)$.

\footnotetext{
${ }^{2}$ Disponível em: https://www.pordata.pt/. Acesso em 28 de maio de 2021.

${ }^{3}$ Disponível em: https://www.pordata.pt/. Acesso em 28 de maio de 2021.
} 


\section{REVISTA DA ABRALIN}

Em ambos os casos, optamos por desconsiderar uma pergunta relativamente a quantos anos de estudo os respondentes haviam concluído por ter sido uma questão que parece ter gerado dúvida entre os participantes, que não deram respostas condizentes com aquelas dadas à pergunta relativa ao seu grau de instrução concluído que, por sua vez, já traz dados suficientes sobre a média do grau de escolaridade dos respondentes.

\subsection{Resultados}

No primeiro questionário, no qual os anúncios tinham sempre imagens diferentes, com diferentes graus de estereotipia e texto verbal igual e neutro ("Faz parte do seu dia"), a maior parte dos respondentes conseguiu identificar de forma exata ou aproximada o grau de estereotipia presente nas representações visuais. Os dois anúncios com imagens neutras, por exemplo, foram avaliados pela maior parte dos inquiridos como sendo "nada estereotipados" ( $\mathrm{N}=6$, em ambos os casos), enquanto os dois exemplos de contra estereótipos foram avaliados como sendo pouco ou nada estereotipados ( $\mathrm{N}=4$ para o contra estereótipo do homem cozinhando e $\mathrm{N}=7$ para o contra estereótipo da mulher profissional). Os anúncios que continham imagens estereotipadas voltadas ao status ocupacional, no caso um com a imagem de uma mulher cozinhando e outro de um homem profissional, também foram identificados como tal, porém de forma levemente mais atenuada, uma vez que em nenhum dos dois casos o resultado apontou para a percepção da presença de um grau extremo de estereotipia. No entanto, os dois anúncios estereotipados voltados aos papéis sociais foram os únicos que não criaram a percepção de estereotipia encontrada na literatura. $O$ anúncio que trazia o estereótipo do homem que tem dificuldades de lidar com o cuidado dos filhos ("bumbling idiot") foi percepcionado como sendo nada ou pouco estereotipado $(\mathrm{N}=8)$, enquanto o que trazia uma mulher com uma expressão sensual foi tido como nada estereotipado $(\mathrm{N}=6)$. Estes resultados podem indicar que os estereótipos de gênero baseados em papéis sociais passam mais facilmente desapercebidos pelo público, talvez por já estarem internalizados, uma vez que são muito comuns na publicidade e na própria percepção que as pessoas possam ter dos gêneros. 


\section{REVISTA DA ABRALIN}

\begin{tabular}{lccccccc}
\hline Imagem & $\begin{array}{c}\mathbf{1} \\
\text { (nada } \\
\text { estereotipado) }\end{array}$ & $\mathbf{2}$ & $\mathbf{3}$ & $\mathbf{4}$ & $\mathbf{5}$ & $\mathbf{6}$ & $\begin{array}{c}\mathbf{7} \\
\text { (extremamente } \\
\text { estereotipado) }\end{array}$ \\
\hline Neutra com homem & $\mathrm{N}=6$ & $\mathrm{~N}=3$ & $\mathrm{~N}=0$ & $\mathrm{~N}=2$ & $\mathrm{~N}=3$ & $\mathrm{~N}=0$ & $\mathrm{~N}=1$ \\
\hline Neutra com mulher & $\mathrm{N}=6$ & $\mathrm{~N}=3$ & $\mathrm{~N}=1$ & $\mathrm{~N}=2$ & $\mathrm{~N}=3$ & $\mathrm{~N}=0$ & $\mathrm{~N}=0$ \\
\hline $\begin{array}{l}\text { Contra estereótipo } \\
\text { homem cozinhando }\end{array}$ & $\mathrm{N}=3$ & $\mathrm{~N}=4$ & $\mathrm{~N}=2$ & $\mathrm{~N}=2$ & $\mathrm{~N}=2$ & $\mathrm{~N}=2$ & $\mathrm{~N}=0$ \\
\hline $\begin{array}{l}\text { Contra estereótipo } \\
\text { mulher profissional }\end{array}$ & $\mathrm{N}=7$ & $\mathrm{~N}=3$ & $\mathrm{~N}=1$ & $\mathrm{~N}=2$ & $\mathrm{~N}=1$ & $\mathrm{~N}=1$ & $\mathrm{~N}=0$ \\
\hline $\begin{array}{l}\text { Estereótipo mulher } \\
\text { cozinhando }\end{array}$ & $\mathrm{N}=2$ & $\mathrm{~N}=0$ & $\mathrm{~N}=3$ & $\mathrm{~N}=1$ & $\mathrm{~N}=5$ & $\mathrm{~N}=2$ & $\mathrm{~N}=2$ \\
\hline $\begin{array}{l}\text { Estereótipo homem } \\
\text { em trabalho analítico }\end{array}$ & $\mathrm{N}=2$ & $\mathrm{~N}=2$ & $\mathrm{~N}=1$ & $\mathrm{~N}=1$ & $\mathrm{~N}=4$ & $\mathrm{~N}=4$ & $\mathrm{~N}=1$ \\
\hline $\begin{array}{l}\text { Estereótipo homem } \\
\text { "bumbling idiot" }\end{array}$ & $\mathrm{N}=4$ & $\mathrm{~N}=4$ & $\mathrm{~N}=2$ & $\mathrm{~N}=1$ & $\mathrm{~N}=0$ & $\mathrm{~N}=2$ & $\mathrm{~N}=2$ \\
\hline $\begin{array}{l}\text { Estereótipo mulher } \\
\text { sensual }\end{array}$ & $\mathrm{N}=6$ & $\mathrm{~N}=3$ & $\mathrm{~N}=0$ & $\mathrm{~N}=1$ & $\mathrm{~N}=2$ & $\mathrm{~N}=1$ & $\mathrm{~N}=2$ \\
\hline
\end{tabular}

TABELA 1 - Variante imagem (texto neutro). Fonte: Elaboração própria.

No segundo questionário, para o qual obtivemos 14 respostas, as imagens eram todas neutras, embora diferentes entre si. Neste caso, optamos por utilizar sempre imagens diferentes pois, por mais que seja comum uma campanha publicitária manter o mesmo texto verbal ainda que utilize diferentes imagens, o contrário não é tão utilizado pelas marcas. Ao menos não quando o texto verbal funciona como a assinatura da campanha, justamente o caso utilizado neste questionário. Assim, apesar das imagens serem diferentes, a assinatura foi o único elemento variável no que diz respeito aos diferentes graus de estereotipia de gênero.

Nos dois exemplos nos quais os textos também eram neutros, a maior parte dos respondentes viu cada um dos anúncios como sendo nada estereotipado ( $\mathrm{N}=5$ e N=4). O mesmo aconteceu com o anúncio que apresentava um contra estereótipo feminino, no qual o texto verbal fazia menção à mulher como profissional ("Depois da jornada de trabalho, ela merece Faygo"), que foi também mais frequentemente votado como não tendo nenhum grau de estereotipia de gênero. No entanto, o exemplo de contra estereótipo masculino, que mencionava o homem como aquele que cuida da coletividade ("Ele sabe o que é melhor para todos") foi entendido como sendo extremamente estereotipado $(\mathrm{N}=4)$. Este, por sinal, foi o único anúncio deste questionário interpretado pela maioria dos respondentes como sendo contrário ao que ele de fato representava, de acordo com a literatura. Isso porque, dentre os anúncios que continham estereótipos, todos foram classificados entre as posições equivalentes a estereotipado e extremamente estereotipado, mesmo sendo todos ligados a estereótipos pertencentes à categoria de papéis sociais. 


\section{REVISTA DA ABRALIN}

\begin{tabular}{lccccccc}
\hline Texto & $\begin{array}{c}\mathbf{1} \\
\text { (nada } \\
\text { estereotipado) }\end{array}$ & $\mathbf{2}$ & $\mathbf{3}$ & $\mathbf{4}$ & $\mathbf{5}$ & $\mathbf{6}$ & $\begin{array}{c}\mathbf{7} \\
\text { (extremamente } \\
\text { estereotipado) }\end{array}$ \\
\hline Neutro & $\mathrm{N}=5$ & $\mathrm{~N}=1$ & $\mathrm{~N}=1$ & $\mathrm{~N}=1$ & $\mathrm{~N}=3$ & $\mathrm{~N}=1$ & $\mathrm{~N}=2$ \\
\hline Neutro & $\mathrm{N}=4$ & $\mathrm{~N}=0$ & $\mathrm{~N}=1$ & $\mathrm{~N}=1$ & $\mathrm{~N}=2$ & $\mathrm{~N}=5$ & $\mathrm{~N}=1$ \\
\hline $\begin{array}{l}\text { Contra estereótipo } \\
\text { mulher profissional }\end{array}$ & $\mathrm{N}=4$ & $\mathrm{~N}=1$ & $\mathrm{~N}=2$ & $\mathrm{~N}=2$ & $\mathrm{~N}=2$ & $\mathrm{~N}=1$ & $\mathrm{~N}=2$ \\
\hline $\begin{array}{l}\text { Contra estereótipo } \\
\text { homem cuidador }\end{array}$ & $\mathrm{N}=3$ & $\mathrm{~N}=1$ & $\mathrm{~N}=1$ & $\mathrm{~N}=1$ & $\mathrm{~N}=2$ & $\mathrm{~N}=2$ & $\mathrm{~N}=4$ \\
\hline $\begin{array}{l}\text { Estereótipo feminino } \\
\text { sensualidade }\end{array}$ & $\mathrm{N}=1$ & $\mathrm{~N}=1$ & $\mathrm{~N}=2$ & $\mathrm{~N}=0$ & $\mathrm{~N}=2$ & $\mathrm{~N}=3$ & $\mathrm{~N}=5$ \\
\hline $\begin{array}{l}\text { Estereótipo masculino } \\
\text { conquistador }\end{array}$ & $\mathrm{N}=0$ & $\mathrm{~N}=2$ & $\mathrm{~N}=0$ & $\mathrm{~N}=1$ & $\mathrm{~N}=4$ & $\mathrm{~N}=3$ & $\mathrm{~N}=4$ \\
\hline $\begin{array}{l}\text { Estereótipo homem não } \\
\text { realiza afazeres do lar }\end{array}$ & $\mathrm{N}=1$ & $\mathrm{~N}=1$ & $\mathrm{~N}=0$ & $\mathrm{~N}=1$ & $\mathrm{~N}=3$ & $\mathrm{~N}=1$ & $\mathrm{~N}=7$ \\
\hline $\begin{array}{l}\text { Estereótipo feminino } \\
\text { mulher cuidadora }\end{array}$ & $\mathrm{N}=3$ & $\mathrm{~N}=0$ & $\mathrm{~N}=0$ & $\mathrm{~N}=2$ & $\mathrm{~N}=2$ & $\mathrm{~N}=4$ & $\mathrm{~N}=3$ \\
\hline
\end{tabular}

TABELA 2 - Variante texto verbal (imagens neutras). Fonte: Elaboração própria.

Curiosamente, apesar da terceira parte do questionário deixar claro o objetivo de se avaliar o impacto do texto verbal nos anúncios que tinham acabado de ser avaliados pelos respondentes, no campo aberto para comentários três pessoas fizeram menção às imagens. Uma dizia que as imagens não estavam claras o suficiente para se identificar um estereótipo, o que comprova o caráter neutro objetivado pela pesquisa para este conjunto de anúncios. Outra comentou que, apesar da importância do elemento textual, as imagens roubavam a sua atenção. E um terceiro respondente apontou a existência de estereotipia nas imagens por considerar não haver diversidade, como por exemplo a presença de pessoas gordas ou com deficiência. Por um lado, isso demonstra que a leitura que fez do termo estereotipia não se limitou ao gênero, como foi pedido no enunciado da questão relativamente à avaliação dos anúncios. Por outro, e somando-se às outras duas respostas, ainda que sejam estatisticamente insuficientes, essas observações podem sugerir uma tendência dos consumidores de avaliarem os estereótipos de forma interseccional e de terem uma pré-disposição para realizar essa avaliação primeiramente através dos argumentos visuais. Há, portanto, um possível indício de que existe algum grau de dificuldade em se avaliar o texto verbal de um anúncio sem que pelo menos alguma influência seja exercida pela imagem. No entanto, ao analisarmos as avaliações dos dois questionários em conjunto, o que se obtém são sinais de que os argumentos visuais têm o potencial de transmitir os estereótipos de gênero de maneira mais sutil do que os verbais, o que leva os consumidores a avaliarem o grau de estereotipia de gênero dos anúncios de forma diferente de acordo com o fato do estereótipo estar sendo comunicado na imagem ou no texto verbal. 


\section{REVISTA DA ABRALIN}

\section{Avaliação dos questionários e pontos de melhoria}

Como referido anteriormente, a terceira parte de ambos os questionários se referia à pesquisa propriamente dita, e tinha como objetivo a coleta de dados sobre alguma possível ambiguidade, falta de clareza ou ausência de rigor que pudessem comprometer o estudo a ser realizado posteriormente com dados mais robustos. Como as perguntas eram rigorosamente as mesmas nos dois questionários, os resultados foram analisados através da somatória de todas as respostas $(\mathrm{N}=29)$. Quando perguntados sobre a clareza do questionário, quase todos os respondentes avaliaram o questionário como sendo claro $(\mathrm{N}=27)$ e a maior parte não se sentiu confusa em nenhuma parte da pesquisa $(\mathrm{N}=22)$. Também a maioria disse não ter encontrado ambiguidades nas questões $(\mathrm{N}=19)$ e acredita que o estudo tem o potencial de alcançar o objetivo a que se propõe, medir a avaliação do público quanto ao grau de estereotipia de gênero em mensagens publicitárias através do texto verbal ou da imagem $(\mathrm{N}=25)$. Dentre aqueles que acreditam ter havido ambiguidades $(\mathrm{N}=10)$, nenhum mencionou posteriormente quais seriam elas.

Há evidências, no entanto, de que uma questão não tenha sido compreendida no contexto correto e, por isso, foi desconsiderada. Isso porque o seu objetivo era compreender se os respondentes haviam sentido algum tipo de viés na pesquisa. Porém, ao cruzar as respostas positivas com a questão relativamente à presença de ambiguidades e a ausência de comentários a este respeito na questão aberta, não fica claro se os respondentes de fato enxergaram algum viés ou se foram confundidos pela forma como a pergunta foi escrita, já que ao invés do termo "viés", perguntamos às pessoas se elas acreditavam que o questionário tentava chegar a algum "objetivo específico". Isso pode ter gerado uma leitura diferente daquela pretendida, uma vez que é necessário que uma pesquisa tenha um objetivo específico, o que não necessariamente significa um viés do estudo.

Entre aqueles que responderam ter encontrado alguma dificuldade em responder o questionário e os que optaram por completar o campo de comentários, alguns expressaram não terem compreendido bem uma questão presente na primeira parte do inquérito, a respeito de quantos anos de escolaridade haviam concluído $(\mathrm{N}=4)$. Por este motivo, e como referido anteriormente, essa foi outra pergunta que acabou por ser desconsiderada na análise dos resultados. Outro dado qualitativo já mencionado é relativo à observação de alguns respondentes quanto a falta de estereotipia clara nas imagens do questionário cuja variável concentrava-se no texto verbal ou até da presença de uma estereotipia generalizada, esta baseada não no gênero, mas em fatores normativos como o peso e a ausência de deficiências ( $\mathrm{N}=3$ ). Um destes respondentes, no entanto, comentou sobre alguma falta de clareza do texto, o que indica uma possível necessidade de melhora na leitura dos anúncios, especialmente naqueles com a variante no texto verbal. Uma pessoa expressou ter tido dúvidas se deveria levar em conta o produto (refrigerante) na sua avaliação sobre estereotipia de gênero, uma sentiu-se confusa a respeito do anúncio com imagem neutra e contra estereótipo masculino, mas não especificou claramente qual foi a dúvida, embora tenha sido uma das pessoas que respondeu acreditar haver ambiguidade na pesquisa podendo, portanto, ser essa a questão. Além disso, dois outros respondentes comentaram que muitas pessoas podem não ter uma definição clara do que é 


\section{REVISTA DA ABRALIN}

gênero, informação que sugerem poder estar contida na pesquisa. São pessoas que também acreditaram haver ambiguidades na pesquisa, podendo existir, portanto, uma ligação entre essa percepção e a falta que sentiram de uma explicação prévia sobre o conceito de gênero.

Isto posto, esta sondagem traz a evidência de que os questionários são claros, cumprem com o seu objetivo e, no geral, não trazem ambiguidades marcantes a ponto de serem comentadas de forma específica. Entretanto, este piloto nos possibilitou notar a necessidade de se melhorar a leitura do texto verbal nos anúncios e de se acrescentar, no enunciado da pesquisa, uma definição clara do que são estereótipos de gênero especificamente e de que a pesquisa trata apenas destes estereótipos e não daqueles voltados a outros temas como peso, idade e deficiências.

\section{Discussão, limitações e conclusões finais}

Embora a pesquisa a respeito do uso de papéis de gênero na publicidade seja razoavelmente constante na academia, parece haver um declínio da presença do tema nas edições mais atuais de revistas de referência. Porém, essa ausência não se dá pelo fim do uso dos estereótipos de gênero nas comunicações das marcas pois, ainda que exista uma tendência de diminuição quanto ao uso deste artifício, ele ainda é predominante nas mensagens publicitárias (FURNHAM; MAK, 1999; FURNHAM; PALTZER, 2010; GRAU; ZOTOS, 2016; EISEND, 2019). E Portugal não parece ser exceção (VERÍSSIMO; PEREIRA, 2006; PEREIRA et al., 2013; JORGE; CERQUEIRA; MAGALHÃES, 2014; PIO, 2019; FERREIRA; LOBO; PIO, 2021). No entanto, tanto em um contexto internacional quanto no panorama português, os estudos existentes focam-se prioritariamente em análises de conteúdo, o que deixa uma lacuna do lado da percepção e da produção. Assim, ao realizar um estudo focado na avaliação que os residentes de Portugal fazem dos diferentes graus de estereótipos de gênero presentes nos argumentos das mensagens publicitárias, damos início a uma importante expansão do campo.

Este estudo piloto traz evidências de que, no geral, quando os estereótipos de gênero estão presentes no texto verbal, eles são mais facilmente percebidos pelo público, mesmo que este tenha a tendência de buscar significados principalmente nas imagens ou em comunhão com elas. Os questionários também apontaram para a existência de uma percepção mais clara dos estereótipos de gênero ligados ao status ocupacional. Já as estereotipias de gênero ligadas a papéis sociais parecem estar mais internalizadas, tornando-se assim mais difíceis de serem percepcionadas. Existe, logo, um claro indício de um baixo grau de literacia por parte dos consumidores do território português quanto ao conceito de estereotipia de gênero. Isso não apenas pela dificuldade de se perceber alguns deles, mas também por ter este sido um dos temas colocados pelos respondentes como um ponto de dificuldade ao responder a pesquisa. Além disso, chama a atenção que, mesmo nos casos em que os estereótipos (e contra estereótipos) foram avaliados pela maioria de forma condizente com aquela encontrada na literatura, praticamente nenhum obteve unanimidade nas mensurações, com representações extremamente estereotipadas sendo avaliadas por alguns respondentes como pouco es-

tereotipadas e representações contra estereotipadas sendo tidas como extremamente 


\section{REVISTA DA ABRALIN}

estereotipadas por parte das pessoas. Tudo isso indica a importância de se entender mais profundamente a literacia do público residente em Portugal quanto aos estereótipos de gênero em diversos contextos e, entre eles, a publicidade. Por este motivo, no desenvolvimento da pesquisa completa poderá ser acrescentado um novo estudo que ajude a comprovar a categorização de estereotipias encontrada em estudos anteriores.

Dentro de uma perspectiva argumentativa, um dos principais contributos da pesquisa é a conclusão de que, mesmo diante de argumentos baseados no fast reasoning, as pessoas são, na maioria das vezes, capazes de identificar a presença da generalização, neste caso através do uso de estereótipos, pelo menos quando a questão é colocada de forma clara. No entanto, ainda mais interessante foi o resultado obtido ao se tentar "isolar" o argumento verbal do imagético, variando o grau de estereotipia em um tipo de argumento, enquanto se manteve o outro neutro. Isso porque assim foi possível levantar evidências de que o argumento verbal acaba por deixar as generalizações dos estereótipos mais explícitas do que as imagens. Assim, pudemos entender um pouco melhor o peso que cada tipo de argumento possivelmente possui na forma como os consumidores interpretam mensagens duo-modais.

Entretanto, e justamente por ser ainda uma pesquisa piloto, este estudo apresenta apenas evidências iniciais, já que possui como principal limitação a amostragem baixa. No futuro, ela deverá se estender não apenas a mais pessoas, mas também a novas faixas etárias, inclusivamente àquelas que abranjam respondentes mais jovens, entre os 14 e os 18 anos, por exemplo. Com uma amostra mais abrangente poderá ser possível também obter um cruzamento mais expressivo de dados, o que pode trazer evidências não apenas a respeito da mensuração dos estereótipos de gênero presente nos argumentos publicitários, mas também sobre a existência, ou não, de mensurações semelhantes entre grupos demográficos similares.

Além disso, mesmo os questionários tendo sido distribuídos de forma aleatória, um deles acabou não propositadamente reunindo um público respondente maioritariamente português e o outro maioritariamente brasileiro. Embora o objetivo da pesquisa sempre foi obter respostas de quem reside em Portugal, ou seja, quem consome as mensagens publicitárias veiculadas no país, e não apenas de pessoas com nacionalidade portuguesa, idealmente a amostra de cada um dos questionários poderia ser mais mista. No entanto, argumentamos que isso não invalida os resultados obtidos por não descaracterizar o público incialmente pretendido de residentes.

O fato de parte, ainda que minoritária, dos respondentes acreditarem que a pesquisa possui ambiguidades porém sem apontá-las também, em nossa percepção, demonstra alguma limitação no que diz respeito aos resultados, limitação que poderia vir a ser neutralizada através de um grupo focal numa fase posterior a este piloto, uma vez que não foi possível realizá-lo a tempo hábil para esta pesquisa, porém anterior ao estudo maior que se tem como objetivo conduzir, após a análise dos dados aqui recolhidos e apresentados. Ainda assim, e por fim, concluímos que este estudo atingiu os objetivos de forma satisfatória tanto do ponto de vista do levantamento de evidências preliminares como do lado da validação, com ajustes, da metodologia e conteúdo utilizado nos questionários 


\section{REVISTA DA ABRALIN}

piloto que poderão ser aperfeiçoados para, em seguida, serem distribuídos a uma amostra maior e mais significativa.

\section{REFERÊNCIAS}

ADAM, J.M.; BONHOMME, M. L'argumentation publicitaire. Paris: Armand Colin, 2012.

AMÂNCIO, L. O gênero no discurso das ciências sociais. Análise Social, Lisboa, v. 38, n. 168, p. 687-714, 2003. Disponível em http://www.jstor.org/stable/41011822.

AN, D.; KIM, S. Relating Hofstede's masculinity dimension to gender role portrayals in advertising: A crosscultural comparison of web advertisement. International Marketing Review, v. 24, n .2, p. 181-207. DOI: $10.1108 / 0265133071074181$.

ARIÈS, P.; DUBY, G. História da vida privada, 1: Do Império Romano ao ano mil. Organizado por Paul Veyne. São Paulo: Companhia de Bolso, 1985.

BLAIR J.A. (2012) The Possibility and Actuality of Visual Arguments. In: TINDALE, C. (Ed.). Groundwork in the Theory of Argumentation. Argumentation Library, v. 21. Windsor: Springer, Dordrecht, 2012, p. 205-22. DOI https://doi.org/10.1007/978-94-007-2363-4_16

BESSENOFF, G. R.; DEL PRIORE, R. E. Women, Weight, and Age: Social Comparison to Magazine Images Across the Lifespan. Sex Roles, v. 56, p. 215-222, 2007. DOI: 10.1007/s11199-006-9164-2.

BIVENS, R.; HAIMSON, O. L. Baking Gender Into Social Media Design: How Platforms Shape Categories for Users and Advertisers. Social Media + Society, v. 2, n. 4, p. 1-12, 2016. DOI: 10.1177/2056305116672486.

BOURDIEU, P. A Dominação Masculina. Oeiras: Celta Editora, 1999.

BUTLER, J. Gender trouble: Feminism and the subversion of identity. New York: Routledge, 1990.

CAVALCANTE, M. M.; CUSTÓDIO FILHO, V. Revisitando o estatuto do texto. Revista do GELNE, v. 12, n. 2, p. 56-71, 2010.

COLTRANE, S.; ADAMS, M. Work-Family Imagery and Gender Stereotypes: Television and the Reproduction of Difference. Journal of Vocational Behavior, v. 50, p. 323-34, 1997. DOI https://doi.org/10.1006/jvbe.1996.1575

DE MEULENAER, S; DENS, N.; DE PELSMACKER, P.; EISEND, M. How consumers' values influence responses to male and female gender role stereotyping in advertising, International Journal of Advertising, v. 37, n. 6, p. 893913, 2018. DOI https://doi.org/10.1080/02650487.2017.1354657

DÖRNYEI, Z.; TAGUCHI, T. Questionnaires in second language research: Construction, administration, and processing (2nd ed.). London: Routledge, 2010.

EISEND, M. A Meta-Analysis of Gender Roles in Advertising. Journal of the Academy of Marketing Science, v. 38, n. 4, p. 418-40, 2010. DOI https://doi.org/10.1007/s11747-009-0181-x

EISEND, M. Gender Roles. Journal of Advertising, v. 48, n. 1, p. 72-80, 2019. DOI

https://doi.org/10.1080/00913367.2019.1566103 


\section{REVISTA DA ABRALIN}

FERREIRA, I.; LOBO, P.; PIO, M. Representações de género na publicidade durante a primeira vaga da pandemia de COVID-19 em Portugal. Revista Comunicação Pública, v. 16, n. 30, 2021. DOI https://doi.org/10.4000/cp.12548

FIGUEIREDO, A. F. F.; PACHECO, D. F. A. Dois corpos objetificados: igualdade nas representações publicitárias? Mediapolis, v. 7, n. 121-136, 2018. DOI https://doi.org/10.14195/2183-6019_7_8

FINSTAD, K. Response Interpolation and Scale Sensitivity: Evidence Against 5-Point Scales. Journal of Usability Studies, v. 5, n. 3, p. 104-110, 2010.

FOWLER, K.; THOMAS, V. A content analysis of male roles in television advertising: Do traditional roles still hold? Journal of Marketing Communications, v. 21, n. 5, p. 356-371, 2015. DOI https://doi.org/10.1080/13527266.2013.775178

FURNHAM, A.; MAK, T. Sex-Role Stereotyping in Television Commercials: A Review and Comparison of Fourteen Studies Done on Five Continents Over 25 Years. Sex Roles, v. 41, p. 413-437, 1999. DOI https://doi.org/10.1023/A:1018826900972

FURNHAM, A.; PALTZER, S. The portrayal of men and women in television advertisements: An updated review of 30 studies published since 2000. Scandinavian Journal of Psychology, v. 51, p. 216-236, 2010. DOI https://doi.org/10.1111/j.1467-9450.2009.00772.x

GOFFMAN, E. Gender advertisements. New York: Harper and Row, 1979.

GRAU, S.; ZOTOS, Y. Gender Stereotypes in Advertising: A Review of Current Research. International Journal of Advertising, v. 35, n. 5, p. 761-70, 2016. DOI https://doi.org/10.1080/02650487.2016.1203556

GROARKE, L. Logic, art and argument. Informal Logic, v. 18, n. 2, p. 105-131, 1996. DOI https://doi.org/10.22329/il.v18i2.2376

HALLIDAY, M. A. K. Language as Social Semiotic: The Social Interpretation of Language and Meaning. London: Edward Arnold, 1978

HOFSTEDE, G.H. Culture's Consequences: International Differences in Work-related Values. Beverly Hills: Sage, 1980.

HURLEY, P. J. A Concise Introduction to Logic. 6. ed. Belmont: Wadsworth, 1997.

IWANIEC, J. Questionnaires: Implications for effective implementation. In: MCKINLEY, J.; ROSE, H. (Eds.). The Routledge Handbook of Research Methods in Applied Linguistics. London: Routledge, 2020, p.324-335.

JORGE, A.; CERQUEIRA, C.; MAGALHÃES, S. PubliDiversidade. Representações sociais e igualdade de gênero na publicidade. Braga: União de Mulheres Alternativa e Resposta, 2014

KACHEL, S.; STEFFENS, M. C.; NIEDLICH, C. Traditional Masculinity and Femininity: Validation of a New Scale Assessing Gender Roles. Frontiers in psychology, v. 7, p. 956, 2016. DOI https://doi.org/10.3389/fpsyg.2016.00956

KNOLL, S.; EISEND, M.; STEINHAGEN, J. Gender roles in advertising. International Journal of Advertising, v. 30, n. 5, p. 867-888, 2011. DOI https://doi.org/10.2501/IJA-30-5-867-888 


\section{REVISTA DA ABRALIN}

KRESS, G. Tense as modality. UEA Papers in Linguistics, v. 5, p. 40-50, 1977.

KRESS, G. Communication and Culture: An Introduction. Sydney, University of New

South Wales Press, 1987

KRESS, G. Multimodality: a social semiotic approach to communication. London \& New York, Routledge, 2010.

KRESS, G.; VAN LEEUWEN, T. Reading images: The grammar of graphic design. London: Routledge, 1996, 2006.

LAMBRECHT, A.; TUCKER, C. Algorithmic Bias? An Empirical Study of Apparent Gender-Based Discrimination in the Display of STEM Career Ads. Management Science, v. 65, n. 7, p. 2947-3448, 2019. DOI https://doi.org/10.1287/mnsc.2018.3093

LAVINE, H.; SWEENEY, D.; WAGNER, S. H. Depicting Women as Sex Objects in Television Advertising: Effects on Body Dissatisfaction. Personality and Social Psychology Bulletin, v. 25, n. 8, p. 1049-1058, 1999. DOI https://doi.org/10.1177/01461672992511012

LIN, C. A. Beefcake versus cheesecake in the 1990s: Sexist portrayals of both genders in television commercials. Howard Journal of Communications, v. 8, n. 3, p. 237-249, 1997. DOI https://doi.org/10.1080/10646179709361757

LOBO, P. Desigualdades de gênero no acesso à esfera pública - Uma análise crítica dos conteúdos noticiosos televisivos [Dissertação de Doutoramento não publicada]. Instituto de Ciências Sociais da Universidade do Minho, 2011. Disponível em: http://repositorium.sdum.uminho.pt/handle/1822/19660

MACAGNO, F., PINTO, R. Reconstructing Multimodal Arguments in Advertisements: Combining Pragmatics and Argumentation Theory. Argumentation, v. 35, p. 141-176, 2021. DOI https://doi.org/10.1007/s10503-020-09525-z

MAGALHÃES, S. Análise de anúncios publicitários em revistas estilo de vida portuguesas: um estudo de caso. In: JORGE, A.; CERQUEIRA, C.; MAGALHÃES, S. (Aut.). PubliDiversidade. Representações sociais e igualdade de gênero na publicidade. Braga: União de Mulheres Alternativa e Resposta, 2014, p. 17- 34.

MARCUSCHI, L. A. A questão do suporte dos gêneros textuais. DLCV: Língua, lingüística e literatura, João Pessoa, v. 1, n. 1, p. 9-40, 2003.

MARSHALL, D.; DAVIS, T.; HOGG, M. K.; SCHNEIDER T.; PETERSEN, A. From overt provider to invisible presence: Discursive shifts in advertising portrayals of the father in Good Housekeeping, 1950-2010. Journal of Marketing Management, v. 30, n. 15-16, p. 1654-1679, 2014. DOI https://doi.org/10.1080/0267257X.2014.945471

MATTHES, J.; PRIELER, M.; ADAM, K. Gender-Role Portrayals in Television Advertising Across the Globe. Sex Roles, v. 75, p. 314-327, 2016. DOI https://doi.org/10.1007/s11199-016-0617-y

MENDES, E. Análise do Discurso e iconicidade: uma proposta teórico-metodológica. In: MENDES, E. et al (Orgs.). Imagem e discurso. Belo Horizonte: FALE, 2013, p. 125-156.

MCARTHUR, L. Z;; RESKO, B. G. The portrayal of men and women in American television commercials. Journal of Social Psychology, v. 97, p. 209-220, 1975. DOI https://doi.org/10.1080/00224545.1975.9923340

MIDDLETON, K.; TURNBULL, S. How advertising got 'woke': The institutional role of advertising in the emergence of gender progressive market logics and practices. Marketing Theory, v. 20, n. 10, p. 1-18, 2021. https://doi.org/10.1177/14705931211035163 


\section{REVISTA DA ABRALIN}

MOTA-RIBEIRO, S. Do outro lado do espelho: imagens e discursos de gênero nos anúncios das revistas femininas - uma abordagem sociosemiótica visual feminista. (Tese de Doutoramento), 2010. Disponível em: http://repositorium.sdum.uminho.pt/handle/1822/12384.

O'DRISCOLL, A. Learning to Sell Sex(ism). Dublin: Palgrave Macmillan, 2019. DOI https://doi.org/10.1007/978-3319-94280-3_1

OSTBERG, J. Thou shalt sport a banana in thy pocket: Gendered body size ideals in advertising and popular culture. Marketing Theory, v. 10, n. 1, p. 45-73, 2010. DOI https://doi.org/10.1177/1470593109355255

PEREIRA, F. C.; VERÍSSIMO, J. A Mulher na Publicidade e os Estereótipos de Gênero. Observatorio (OBS*) Journal, v. 5, p. 281-296, 2008. DOI: https://doi.org/10.15847/obsOBS222008120

PEREIRA, F. C.; VERÍSSIMO, J.; DIAZ, A. C.; CORREIA, R. Gender stereotyping, sex and violence in Portuguese and Spanish advertisement. Comunicação e Sociedade, v. 23, p. 274-292, 2013.

PIO, M. O paradoxo Surf: a ambiguidade do discurso e o que isso diz sobre sua audiência. Um estudo de caso do spot do detergente Surf para o Youtube. Revista Rhêtorikê, v. 6, p. 37-56, 2019. DOI

https://doi.org/10.25768/fal.r.n06.a02

POLLAROLI, C.; ROCCI, A. The argumentative relevance of pictorial and multimodal metaphor in advertising. Journal of Argumentation in Context, v. 4, p. 158-199, 2015. DOI https://doi.org/10.1075/jaic.4.2.02pol

REICHERT, T.; CARPENTER, C. An Update on Sex in Magazine Advertising: 1983 to 2003. Journalism E Mass Communication Quarterly, v. 81, n. 4, p. 823-837, 2004. DOI https://doi.org/10.1177/107769900408100407

REICHERT, T.; LATOUR, M. S.; LAMBIASE, J. J.; ADKINS, M. A Test of Media Literacy Effects and Sexual Objectification in Advertising. Journal of Current Issues \& Research in Advertising, 29(1), 81-92. DOI https://doi.org/10.1080/10641734.2007.10505210

TANAKA, K. Advertising Language. A Pragmatic Approach to Advertisements in Britain and Japan. London e New York: Taylor \& Francis Routledge, 1994.

SANTOS, C. F. Beleza, magreza e juventude: a perfeição corporal feminina na publicidade e a corporeidade disruptiva da Dove. Comunicación, v. 3, n. 5, p. 13-27, 2016. Disponível em: https://revistas.upb.edu.co/index.php/comunicacion/article/download/1476/1289/2453

TOULMIN, S. Los usos de la argumentación. Barcelona: Ediciones península, 1958.

TSERONIS, A.; FORCEVILLE, C. Introduction. Argumentation and rhetoric in visual and multimodal communication. In: TSERONIS, A.; FORCEVILLE, C. (Eds.). Multimodal argumentation and rhetoric in media genres, Amsterdam: John Benjamins, 2017, p. 2-24.

URAY, N.; BURNAZ, S. An Analysis of the Portrayal of Gender Roles in Turkish Television Advertisements. Sex Roles, v. 48, p. 77-87, 2003. DOI https://doi.org/10.1023/A:1022348813469

VAN EEMEREN, F.; GROOTENDORST, R. Argumentación, comunicación y falacias.

Una perspectiva pragmadialéctica. Ediciones Universidad Católica de Chile: Chile, 2002.

VAN EEMEREN, F. In Context: Giving contextualization its rightful place in the study of argumentation. Argumentation, v. 25, p. 141-161, 2011. DOI https ://doi.org/10.1007/s1050 3-011-9211-1. 


\section{REVISTA DA ABRALIN}

VERÍSSIMO, J.; PEREIRA, F. J. Women in Portuguese advertising. In: INTERNATIONAL CONFERENCE ON RESEARCH IN ADVERTISING, 2006, Bath.

VERÍSSIMO, J. O corpo na publicidade. Lisboa: Edições Colibri/Instituto Politécnico de Lisboa, 2008.

WALTON, D. What is reasoning? What is an argument? Journal of Philosophy, v. 87, n. 8, p. 399-419, 1990. DOI https ://doi.org/10.2307/20267 35 .

WALTON, D. Rethinking the Fallacy of Hasty Generalization. Argumentation, v. 13, p. 161-182, 1999. https://doi.org/10.1023/A:1026497207240

WALTON, D. Why Fallacies Appear to Be Better Arguments than They Are. Informal Logic, v. 30, n. 2, p. 159-184, 2010. Disponível em: https://ssrn.com/abstract=1759289

WILLIAMSON, J. Decoding Advertisements: Ideology and Meaning in Advertising. London: Marion Boyars Publishers Ltd, 1978.

WINDELS, K. 'Stereotypical or Just Typical: How Do US Practitioners View The Role and Function of Gender Stereotypes in Advertisements?' International Journal of Advertising, v. 35, n. 5, p. 864-87, 2016. DOI https://doi.org/10.1080/02650487.2016.1160855

WOLF, N. O mito da beleza. Como as imagens de beleza são usadas contra as mulheres. Rio de Janeiro: Rocco, 1992. 